\title{
The impact of the circular economy on the pro- ecological behaviour of consumers in Russia
}

\author{
Inna Lazanyuk $^{1,}{ }^{*}$, Svetlana Ratner $^{1,2}$, Konstantin Gomonov ${ }^{1}$, Svetlana Revinova ${ }^{1}$ and Swati \\ Modi $^{3}$ \\ ${ }^{1}$ Department of economic and mathematical modelling, Peoples' Friendship University of Russia \\ (RUDN University), 6 Miklukho-Maklaya Street, Moscow 117198, Russian Federation \\ ${ }^{2}$ Economic dynamics and innovation management laboratory, V.A. Trapeznikov Institute of Control \\ Sciences, Russian Academy of Sciences, 65 Profsoyuznaya Street, Moscow 117997, Russian \\ Federation \\ ${ }^{3}$ Department of Management, GLS Institute of Business Administration, GLS University, \\ Ahmedabad, India
}

\begin{abstract}
Russia is at the beginning of the development of a circular economy (CE). The development of pro-ecological behavior is one of the main goals to transition to circular patterns of production and consumption. The lack of readiness of technologies and infrastructure to support consumer behavior patterns can inhibit pro-ecological consumer patterns. However, world experience shows that cultural and economic barriers have the most significant impact on which of the practices of pro-environmental behavior are spreading and which are not. The study aims to analyze the reasons for the popularity and unpopularity of the patterns of proecological behavior among Russia's population. The research methodology is based on a developed questionnaire of 57 practices and aimed at assessing consumer responsiveness in pro-environmental behavior. The processing of the survey results carried out using descriptive and nonparametric statistics. This study argued that widespread adoption of circular economy approaches would require profound changes in manufacturing practices and consumption patterns. The results showed that environmental competence is influenced by external and internal factors that can coordinate the education process.
\end{abstract}

\section{Introduction}

A circular economy presupposes the development and operation of an effective business model that seeks to replicate the closed natural chain. Moving towards CE requires a paradigm shift in the way things work, making sustainable development and self-contained thinking at the heart of business models and industrial organizations. Since 2015, the EU has been implementing an action plan for the development of a circular economy (updated in 2018), which establishes a set of measures covering the entire life cycle of a product: from production and consumption to waste management and the market for secondary raw

\footnotetext{
* Corresponding author: lazanyuk-iv@rudn.ru
} 
materials [1]. Measuring progress towards a circular economy is carried out in four dimensions: production and consumption; waste management; secondary raw materials; competitiveness and innovation. Indicators of the circular economy, including in the monitoring structure, have been developed in these areas. The development of a circular economy in the EU has already generated 4 million jobs, 147 billion euros in added value and an inflow of 17 billion euros in private investment [2].

The implementation of the principles of a circular economy in Russia is at an early stage. Elements of a circular economy reflected in many strategic planning documents of the Russian Federation. In the Strategy of Economic Security of the Russian Federation for the period up to 2030, the Forecast of the Russian Federation's scientific and technological development for the period up to 2030 establishes long-term vectors of innovative hightech development, taking into account the ever-increasing environmental risks. One of the main directions of the spatial development of the Russian Federation for the period up to 2025 is determined to improve the state of the environment, stimulate the introduction of innovative and environmentally friendly technologies, develop an effective waste management system, including the development of the waste treatment and disposal industry [3]. Implementing the idea of a circular economy requires rethinking the value chain, a conscious consumer approach, and the use of new business models such as sharing platforms to extend product lifespan [4].

The European Development Plan for a Circular Economic is one of the best-developed practical guidelines for transforming current economic conditions to new and more sustainable patterns of production and consumption [5]. The immaturity of technology and infrastructure to support consumer behavior patterns can inhibit the adoption of proecological consumer behavior patterns. Analysis of literature sources in sustainable development shows that cultural and economic factors have the most significant impact on the spread or non-proliferation of pro-ecological behavior practices [6-8].

The main principles of state policy in waste management are the following: protection of human health, maintenance or restoration of a favorable state of the environment and conservation of biological diversity. As well as a scientifically grounded combination of society's environmental and economic interests to ensure sustainable development of society; use of the best available technologies (BAT) for waste management; participation in international cooperation of Russia in the field of waste management, etc. Economic incentives for waste management activities include introducing BATs covering the use of low-waste and resource-saving technologies and equipment. Incentives are also needed to implement the principle of "extended" producer responsibility (EPR), introducing an ecological fee, benefits for payments for negative impact on the environment when introducing technologies that reduce the amount of waste, etc.

The introduction of new principles of functioning of the economy, associated with the transition to a closed-cycle economy, requires a collective consciousness change. Consumers' willingness to change traditional patterns should be formed gradually, with the transition from simple practices of resource conservation and waste management to more complex ones.

This study investigates the circular economy's influence on pro-environmental behavior and the popularity of different practices among the Russian people. To assess the popularity of the practical application, we used age, the economic activity of respondents, and participation in the educational process. This work complements the literature by offering new empirical evidence of consumer attitudes towards various forms of pro-ecological behavior in Russia and its cultural influences. The study was conducted by polling a group of consumers, to which students of the Peoples' Friendship University of Russia (Moscow) and the Kuban State University (Krasnodar) were selected. 


\section{Materials and methods}

In compiling the list of practical pro-environmental behavior as a basis for the study was taken [6]. In the previous phase of the study based on an analysis of modern works on selected topics, an expanded list of 57 practices of pro-environmental behavior contributed to forming models and mechanisms of circular economy, mainly through resource conservation and waste handling. Can find more details on the list of practices used for the analysis in work [9].

We conducted a survey of a group of respondents (623 people) of different ages, income levels, education, and various activity fields. The study's main focus was on determining the statistical relationships between age, involvement in the educational process, and economic activity on the frequency of application of pro-ecological behavior practices. The search for answers to the research questions carried out using the descriptive statistics method. To verify the results of processing statistical hypotheses also used methods of nonparametric statistics.

\section{Results}

The descriptive statistics of the results show that Russian consumers are moderately aware of the information about «green» products, which the company usually disseminates either through labeling of their products or through environmental advertising. Consumers also have a positive and moderate intention to buy organic products. But their knowledge of circular economics, caring for the environment and ecological behavior has yet to be enhanced. The correlation of variables is significant for the green purchase intent of consumers. We did not include tables with descriptive statistics and correlation analysis due to the limited number of pages.

\subsection{Results of the analysis of descriptive statistics on pro-environmental behavior practices}

The calculation of descriptive statistics on the respondents' assessments of the frequency of using the proposed patterns of pro-ecological consumer behavior shows that the most popular practices across all 57 were:

P2 "Reducing the opening and closing of the refrigerator door",

P4 "Putting hot food into the refrigerator after cooling",

P8 "Turning off lights in empty rooms",

P10 "Turning off the TV when people are not watching",

P11 "Using energy-saving mode or turning off when not in use", they have a median score of 2.7 to 3 .

The least popular practices, with a median score of 1.5 to 2.1 , are: P33 "Throwing away kitchen garbage after it has dried",

P49 "Joining the one day without car program",

P53 "Maintaining the air pressure in the tire",

P55 "Using the dishwasher",

P57 "Using residual heat when cooking on an electric stove» (fig. 1). 


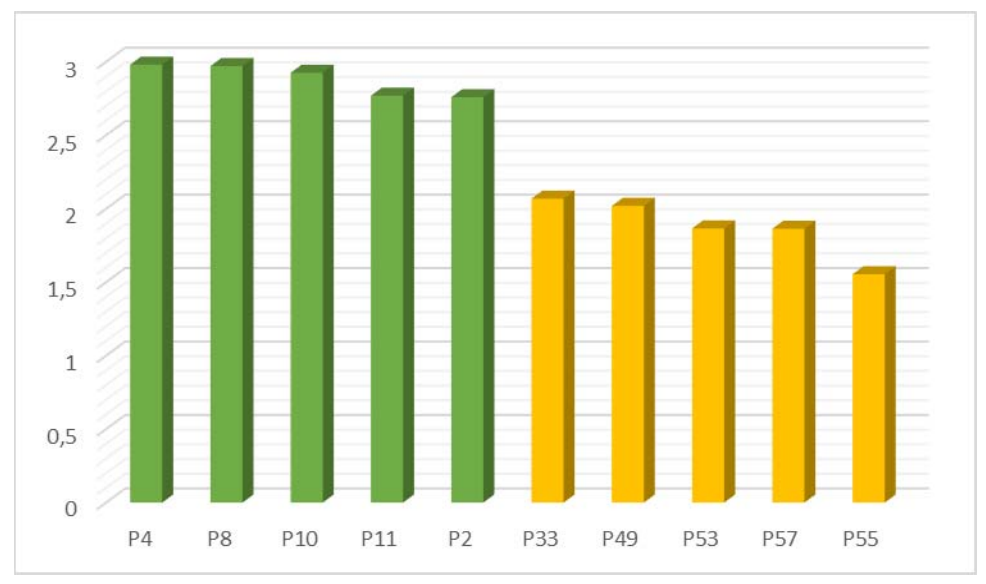

Fig. 1. Average ratings of 5 most and five least popular practices of pro-ecological behavior in Russia

Among the groups of practices, the most popular were Energy-saving practices (median 2.8, average 2.6), the least popular practices for waste management (median 1.9, average 2.21) (fig. 2).

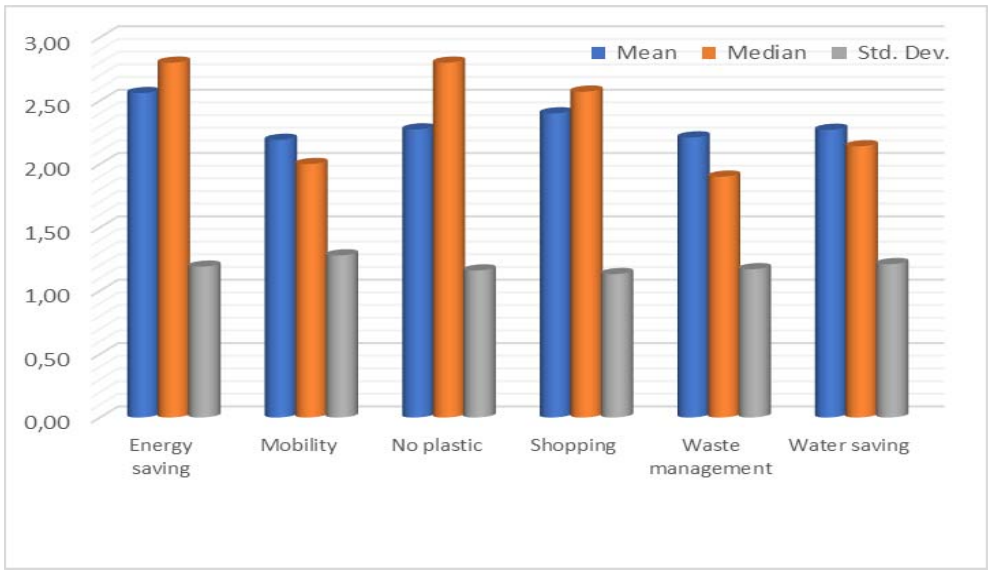

Fig. 2. Most popular groups of practices

These studies have shown that a significant percentage of citizens $(46 \%)$ try to save electricity, water and gas. On keeping resources in everyday life, the separation of waste, following the standards of waste management survey showed that Russians rarely adhere to a few simultaneously pro-ecological practices, but individually used quite often. The most frequently chosen reason for not applying pro-ecological practices for handling household waste was the answer "No necessary conditions for use". We assume that the overwhelming majority of respondents could use this practice more often, given the right conditions.

\subsection{Results of the influence of the respondent's age and involvement in the educational process on the frequency of application of the practice of pro- ecological behavior}

The majority of respondents (63\%) belong to the age categories from 18 to 29 years old, which allows us to test the hypothesis about the influence of education on the respondent's attitude to pro-ecological behavior practices. Since some respondents' age categories are 
less represented in the sample, we used nonparametric statistics methods to process the research results, allowing us to work with small samples. Calculation of nonparametric correlation coefficients Spearman $(\mathrm{R})$ and Tau-Kendall $(\mathrm{K})$ revealed the presence of statistically significant relationships between the respondent's age and his attitude to various practices of pro-ecological behavior. As shown by the nonparametric correlation results, the older generation more often practices more than $50 \%$ of the main patterns of pro-ecological behavior.

We conducted a series of nonparametric Mann-Whitney tests that revealed statistically significant differences in the use of some pro-ecological behavior practices between respondents involved in the learning process (schoolchildren, students) and those who completed their education. The revealed statistically significant differences between the groups of respondents who are receiving education and who completed their education showed that the second group of respondents demonstrates more conscious pro-ecological behavior in absolutely all aspects.

\subsection{The results of the relationship between the grouping variable - economic activity and the frequency of application of practices of pro-ecological behavior}

Economically active includes all employed respondents, regardless of the type of employment (self-employed, a sole proprietorship, an employee in the enterprise) and students. The economically inactive group includes pensioners, housewives, persons on parental leave, or persons with disabilities. Such a subdivision of the respondents in the group performed to test how free time (it is believed that economically active people have less free time) affects the frequency of use of various practices of pro-environmental behavior. The revealed differences confirm the hypothesis that economically active respondents demonstrate greater environmental awareness and more often practice collection and return for recycling waste paper, glass containers, e-waste, and reusable shopping bags. Also, economically active respondents are more competent in handling household appliances to reduce their energy consumption.

\subsection{Effect of educational level on the frequency of usage practices pro- environmental behavior}

The level of education of the respondents is generally high. The majority of respondents $(62 \%)$ have completed higher education (31\% - bachelor's level and another $41 \%$ specialist or master's level). Another $6 \%$ of respondents have postgraduate education postgraduate, doctoral, or residency), $16 \%$ of respondents have secondary education $(6 \%$ general and $10 \%$ - vocational) and another 16\% - incomplete higher. We tested the hypothesis about the influence of the respondent's educational level on his attitude to various pro-ecological behavior practices by calculating the Spearman (R) and Tau-Kendall (K) nonparametric correlation coefficients. The coefficients' calculations made it possible to identify weak positive statistically significant coefficients, level $p=0.05$ with a series of non-trivial practices. We can note that some of the Waste Management category practices in the Avoiding Plastic category and the Shopping category are relatively new to the Russian consumer and are labor-intensive. Thus, it is possible to confirm the positive influence of the respondent's education level on the formation of a pro-ecological model of consumer behavior. 


\section{Discussion}

In the literature on the issues of pro-ecological behavior, we can distinguish several articles that consider various factors and barriers affecting environmental responsibility formation, which presupposes a more efficient use of natural resources.

In a study [10] on the example of European countries, the author showed evidence of a positive influence of education on pro-ecological behavior. Our work results also confirmed a positive correlation between involvement in the educational process and the attitude of respondents to pro-ecological practices. We found statistically significant differences between the groups of respondents receiving education and those who completed it; we also received confirmation that the second group of respondents demonstrates more conscious pro-ecological behavior in absolutely all aspects.

In the article [11], the authors identified the most significant factors: age, income, and housing type. We did not take into account income and type of housing in this study. But the results of our study confirmed the effect of age on the frequency of practice. We found that the older generation is more conscientious about their consumption in many practices. It is important to note that this fact is not associated with a decrease in economic activity and, consequently, a reduction in income. The main reasons for not applying some consumer behavior patterns are either a lack of understanding of their significance or a complete lack of information about the possibility of such consumer behavior.

When processing the data, we identified significant shortcomings in the questionnaire that we used in this study. This method is actively discussed in the literature $[7,8,13]$. At the stage of conducting primary research to obtain a general picture of the spread of a particular model of behavior and identify the reasons for the non-proliferation of other models, this method, in our opinion, remains a priority tool.

As the key factors that hinder environmentally sound behavior, the respondents highlight the lack of their initiative and specific environmental nature measures.

\section{Conclusions}

This study's main results are as follows: the most popular practice followed by respondents are those who have developed household habits or those that can bring tangible material benefits in the current economic conditions. A higher level of involvement in education reduces the consumption of electricity. There are two possible cooperation areas - people are more conscious of consuming or resource initially acquire goods. Economically active respondents demonstrate a greater awareness of nature and often practice proenvironmental behavior.

Waste management practices are the least popular. We attribute the unpopularity of the waste management practice to the underdeveloped "green" infrastructure in Russia. It is a serious barrier to the formation of pro-ecological behavior. Analysis of the differences in students' pro-ecological behavior and non-students made it possible to identify some problem areas of the modern Russian education system. Ignoring student youth's available practices of pro-environmental behavior indicates insufficient attention to environmental and sustainable development issues in school and university educational programs. At the same time, the educational system has enormous potential for the formation of conscious consumption practices in the process of direct learning and creating an appropriate educational environment. 


\section{Future research}

Our research focused on the impact of the circular economy on the ecological behavior of consumers. Still, the circular economy focuses more on reducing environmental degradation by redirecting the flow of resources. Consumers' environmental behavior plays a partial role as there are some other vital factors: producer, seller, other economic agents, etc. to build a circular economy. Therefore, further research is needed to show the circular economy's overall impact on other areas in line with its objectives.

The acknowledgements. The publication has been prepared with the support of the grant of the President of the Russian Federation for young scientists-candidates of sciences MK-5006.2021.2

\section{References}

1. Circular economy, Overview, Eurostat. URL: https://ec.europa.eu/eurostat/web/circular-economy

2. Which indicators are used to monitor the progress towards a circular economy? // Eurostat. URL: https://ec.europa. EU/Eurostat/web/circular-economy/indicators

3. Strategiya prostranstvennogo razvitiya RF na period do 2025 goda // https://www.economy.gov.ru/material/file/a3d075aa813dc01f981d9e7fcb97265f/1302 19_207-p.pdf

4. S. Revinova, S. Ratner, I. Lazanyuk, K. Gomonov, Sharing Economy in Russia: Current Status, Barriers, Prospects and Role of Universities. Sustainability, 12, 4855, (2020) https://doi.org/10.3390/su12124855

5. S. Ratner, European experience in transition to circular economy. Economic Analysis: Theory And Practice, 19(4), 598-617, (2020) https://doi.org/10.24891/ea.19.4.598

6. H. Lee, K. Kurisu, K. Hanaki, K, Influential Factors on Pro-Environmental Behaviors-A Case Study in Tokyo and Seoul. Low Carbon Economy, 04(03), 104116, (2013) https://doi.org/10.4236/lce.2013.43011

7. C. Kormos, R. Gifford, The validity of self-report measures of proenvironmental behavior: A meta-analytic review. Journal Of Environmental Psychology, 40, 359-371, (2014) https://doi.org/10.1016/j.jenvp.2014.09.00

8. F. Lange, S. Dewitte, Measuring pro-environmental behavior: Review and recommendations. Journal Of Environmental Psychology, 63, 92-100, (2019) https://doi.org/10.1016/j.jenvp.2019.04.009

9. S. Ratner, I. Lazanyuk, S. Revinova, K. Gomonov, K. Barriers of Consumer Behavior for the Development of the Circular Economy: Empirical Evidence from Russia. Appl. Sci. 11, 46, (2021) https://doi.org/10.3390/app11010046

10. A. Meyer, Does education increase pro-environmental behavior? Evidence from Europe. Ecological Economics, 116, 108-121, https://doi.org/10.1016/j.ecolecon.2015.04.018

(2015)

11. J. Martinsson, L. Lundqvist, A. Sundström, Energy saving in Swedish households. The (relative) importance of environmental attitudes. Energy Policy, 39(9), 5182-5191, (2011) https://doi.org/10.1016/j.enpol.2011.05.046

12. F. Kaiser, M. Merten, E. Wetzel, How do we know we are measuring environmental attitude? Specific objectivity as the formal validation criterion for measures of latent attributes. Journal Of Environmental Psychology,55, 139-146, (2018) https://doi.org/10.1016/j.jenvp.2018.01.003 